\title{
Implementasi Kebijakan Pembangunan Infrastruktur Jalan Kawasan Ekonomi Khusus Kota Bitung

\author{
G. H. Tumbel ${ }^{\text {a, }}{ }^{*}$, Jetty E. H. Mokat ${ }^{\text {b, }}{ }^{\text {, }}$, Ratni Yunansi Podomi ${ }^{\text {c, } 3}$
} \\ ${ }^{a}$ Universitas Negeri Manado, Ilmu Administrasi Negara, Tondano, Indonesia \\ 1 goinpeacetumbel@unima.ac.id; jettymokat@unima.ac.id; ratnipodomi@gmail.com
}

\section{INFO A R T IKEL}

Diterima 00 April 00

Disetujui 00 Oktober 00

Key word:

Border Crossing

Agreement

Agreement Bias

Policy Update

\section{A B S T R A C T}

The Indonesia - Philippines Agreement on Border Crossing Agreement has been running for more than 30 (thirty) years. The results of previous research show that the Indonesia - Philippines agreement on borders is biased from what is contained in it. The Border Crossing Agreement (BCA) regulates 3 things, namely family relationships, religious activities and pleasure [1]. In fact, the cross-border relationship between two residents at the border has developed into trade relations, to the point of joint fishing activities whose mechanisms have not been regulated in the statutory system. Previous research has also shown that under these conditions and due to different domestic policies, the greater benefits are enjoyed by the Philippines, therefore it is very urgent to immediately update the border agreement between the two countries, and formulate related policies. with the management of the border area, namely the Talaud Islands Regency. This study seeks to produce concrete policy formulations regarding the regulation of cross-border relations between the people of the Talaud Islands Regency and the South Philippines, so that the benefits of this cross-border relationship are balanced. The results of this study are expected to become content of the formal regulations governing population relations between these two regions.

INTISARI

\section{Kata kunci:}

Implementasi Kebijakan,

Kawasan, Infrastrutur Jalan
Penelitian ini bertujuan untuk dapat mengetahuibagaimanaImplementasi Pembangunan Infrastruktur Jalan Kawasan Ekonomi Khusus Kota Bitung. Penelitian ini menggunakan pendekatan kualitatif, dengan teknik pengumpulan data melalui: observasi, wawancara dan dokumentasi. Sumber data dengan wawancara terstruktur yaitu di kantor Administrator Kawasan Ekonomi Khusus Kota Bitung dan masyarakat kec.Matuari. Hasil temuan penelitian menunjukan bahwa 1) aturan terkait pembangunan KEK bitung tidak efektif karena diberhentikan sementara disebabkan masyarakat setempat yang menolak pembangunan dilanjutkan mengakibatkan pembangunan lanjutan jalan kawasan tidak terlaksana, 2) tidak terlaksananya pembangunan lanjutan dikarenakan tidak ada kepastian kepemilikan lahan yang mengakibatkan pembangunan tersebut diberhetikan sementara. Sedangkan dalam UU No. 239 tahun 2009 dijelaskan bahwa Pembangunan kawasna ekonomi khusus difasilitasi dengan 3 fasilitas yaitu Kantor Administrator, Jalan Poros kawasan, dan perumahan pekerja sejalan dengan PP No. 32 tahun 2014 tentang kawaan ekonomi khusus kota bitung yang mengatur tentang dena dan masterplapembangunan kawasan ekonomi khusus. faktor-faktor determinan penyebab aturan sosialisasi dan memberikan pemahaman kepada masyarakat mengenai maksud dan tujuan KEK agar mempermudah masyarakat memahami agar masyarakat bisa berpartisipasi.

Copyright (C) 2019 (Goinpeace Tumbel). All Right Reserve

\footnotetext{
* Korespondensi Penulis ; e-mail: ${ }^{1}$ goinpeacetumbel@unima.ac.id
} 
Ekonomi Khusus Kota Bitung Oleh Pemerintah Provinsi Sulawesi Utara yang telah diajukan kepada Dewan Nasional Kawasan Ekonomi Khusus dan telah melakukan Pengkajian, dan disetujui usulan pembentukan KEK tersebut kemudian Dewan Nasional Kawasan Ekonomi Khusus mengajukan rekomendasi penetapannya kepada Presiden. Maka ditetapkannya Peraturan Pemerintah No. 32 tahun 2014 tentang Kawasan Ekonomi Khusus Kota Bitung yaitu Peraturan Pemerintah No. 32 Tahun 2014 yang telah sesuai dengan ketentuan peraturan perundangundangan mengenai Kawasan Ekonomi Khusus yang dalam hal ini di sebut Kebijakan. Pembentukkan Kawasan Ekonomi Khusus di Wilayah

Provinsi Sulawesi Utara yaitu di Kota Bitung karena Kota Bitung memiliki Potensi geoekonomi dan geostrategis [8].Pembangunan Kawasan Ekonomi khusus di fasilitasi dengan 3 fasilitas pendukung yaitu Kantor Administrator, Jalan Poros Kawasan dan Perumahan bagi pekerja. Dalam proses pembangunan Infrastruktur pendukung yaitu dalam hal ini Jalan poros kawasan di Kawasan Ekonomi Khusus Kota Bitung, pada saat dilakukan pekerjaan lanjutan terhambat oleh masyarakat dengan alasan bahwa lahan area pembangunan lanjutan jalan tersebut merupakan lahan milik masyarakat namun lahan tersebut diatur dalam Peraturan Pemerintah Nomor 32 Tahun 2014 adalah lahan untuk pembangunan kawasan ekonomi khusus, dan juga di dukung oleh sertifikat HPL No. 2 tahun 2018.

Dari masalah tersebut maka rumusan masalahnya adalah : 1) Bagaimana Implementasi Kebijakan Pembangunan Infrastuktur Jalan Kawasan Ekonomi Khusus Kota Bitung? Dan 2) Apa saja faktor-faktor determinan pada pembangunan infrastruktur jalan kawasan ekonomi khusus kota bitung?

\section{Metode Penelitian}

Penelitian ini menggunakan jenis penelitian kualitatif [1]. Dengan maksud memahami makna di balik fakta, yang berkaitan dengan Implementasi Pembangunan Infrstrutur Jalan Kawasan Ekonomi Khusus, Tujuan untuk mengetahui bagaimana Implementasi Kebijakan Pembangunan Infrastruktur Jalan Kawasan Ekonomi Khusus Kota Bitung dengan teknik pengumpulan data dengan wawancara, observasi, dokumentasi. Analisa datanya dengan melakukan triangulasi antara data dokumen berupa peraturanperaturan mengenai Kawasan Ekonomi Khusus. Wawancara terstruktur dilakukan kepada Staf Pegawai kantor administrator dan Masyarakat

Kecamatan Matuari yang tinggal di daerah pembangunan infrastrutur jalan kawasan.

\section{Hasil dan Pembahasan}

Model Implementasi Kebijakan Pembangunan Infrastruktur Jalan Kawasan Ekonomi
Khusus Kota Bitung terkait dengan pembangunan infrastruktur jalan kawasan. Berdasarkan dari hasil penelitian yang telah dilakukan oleh peneliti maka dapat bahwa Implementasi Kebijakan Pembangunan Infrastruktur Jalan Kawasan Ekonomi Khusus Kota Bitung belum berjalan dengan baik karena berdasarkan pada temuan yaitu: Terhambat masalah pembebasan lahan dimana masyarakat di daerah pembangunan jalan Kawasan menolak pembangunan dilanjutan dengan alasan bahwa lahan tersebut adalah milik masyarakat. Tidak ada informasi yang diterima masyarakat mengenai Pembangunan Jalan tersebut. dan juga dalam Proses pengawasan pembangunan infrastruktur jalan kawasan dilakukan langsung oleh

Dewan Nasional Kawasan Ekonomi Khusus, dan di dampingi oleh dua orang dari kantor administrator kawasan ekonomi khusus yaitu salah satunya dalah kepala kantor administrator kawasan ekonomi khusus kota bitung Pemerintah sudah tidak mengetahui berapa kali pengawasan yang dilakukan. Pemerintah sudah mengatahui peraturan yang menjadi acuan pembangunan kawasan ekonomi khusus kota bitung,. Kamudian juga terjadi penggusuran pada tanggal 5 februari 2016 di daerah Pembangunan jalan kawasan yaitudi kec. Matuari Kota Bitung, Masyarakat menuntut adanya ganti rugi lahan untuk tempat pemukiman baru jika proses pembangunan jalan akan dilanjutkan. Masyarakat setempat adalah masyarakat illegal yang tidak ada bukti kepemilikan lahan, sebab lahan tersebut adalah lahan negara atau tanah pemerintah dan pembangunan akan tetap dilanjutkan secepatnya.

Rumah susun yang pemerintah sediakan untuk masyarakat disekotar lahan kawasan sudah ada, tetapi masyarakat tetap tidak setuju jika harus pindah di rumah susun tersebut. Lahan untuk pembagunan jalan kawasan ekonomi khusus adalah tanah milik negara berdasarkan sertifikat HPL nomor 2 tahun 2018 yaitu tanah tersebut milik pemerintah provinsi Sulawesi utara. Masyarakat setempat tidak ada bukti kepemilikan lahan tersebut. pembangunannya diberhentikan sementara.

Berdasarkan hasil temuan terkait penelitian yang peneliti temukan dilapangan, yang menyangkut faktor-faktor determinan dalam implementasi kebijakan Pembangunan Infrastruktur jalan kawasan ekonomi khusus kota bitung yaitu 1).Komunikasin, 2) Kondisi lingkungan Sosial, Ekonomi dan Politik , 3) Pembiayaan program dan keiatan, 4) Partisipasi Masyarakat.. Indikator tersebut dianggap mempunyai peran yang penting dalam melihat faktor-faktor determinan dalam implementasi kebijakan infrastruktur jalan kawasan ekonomi khusus kota bitung.

\section{Komunikasi}

Komunikasi sebagai proses penyampaian informasi komunikator kepada komunikan. Informasi mengenai kebijakan publik perlu disampaikan kepada pelaku kebijakan agar para pelaku kebijakan dapat mengetahui apa yang harus 
mereka persiapkan dan lakukan untuk menjalankan kebijakan tersebut sehingga tujuan dan sasaran kebijakan dapat dicapai sesuai yang diharapkan [2]. Sudah terlihat jelas bahwa permasalahan yang ada di indikator ini adalah masyarakat tidak memahami tentang maksud dan tujuan pembangunan infrastruktur jalan kawasan ekonomi khusus sebab tidak adanya sosialisasi secara langsung dari pihak

ikasi dan koordinasi dimana komunikasi ini lebih mempermudah proses implementasi dari suatu kebijakan.

\section{Kondisi Linkungan Sosial, dan Politik}

Ekonomi

Kondisi lingkungan sosial, ekonomi dan politik tidak dapat dipisahkan dari implementasi kebijakan, dimana dalam proses impelemntasi kebijakan perlu melihat kondisi lingkungan sosial, ekonomi dan politiknya, sebab jika kondisi lingkungannya mendukung maka akan lebih mempermudah bahkan bisa mendorong dalam proses implementasi kebijakan tersebut. Namun dalam penelitian pembangunan infrastruktur jalan kawasan ekonomi khusus ini dimana proses pembangunanya dilakukan di lahan milik negara jadi, tidak ada orang yang menempatinya, tetapi yang pada kenyataanya ada masyarakat yang tinggal di lahan tersebut sedangkan masyarakat tersebut tidak ada bukti kepemilikan yang sah. Dijelaskan dalam model teori Van meter van Horn yaitu Kondisi Lingkungan sosial, ekonomi dan politik. Dengan kondisi lingkungan sosial, ekonomi dan politik masyarakat dan pembangunan infrastruktur jalan kawasan ini, masih dicari jalan terbaik dan pembangunan infrastrukturnya akan secepatnya dilanjutkan.

\section{Pembiayaan Program dan Kegiatan}

Pembiayaan program dan kegiatan dibiayai melalui APBD yang disetujui oleh Dewan Kawasan Ekonomi Khusus, tidak ada pembiayaan untuk ketersediaan lahan sebab, pembangunan infrastruktur jalan kawasan ini di lakukan di lahan milik negara. Dan masalah yang ditemui dalam indikator ini yaitu masyarakat yang menuntut adanya pembiayaan untuk lahan kawasan yang mereka tempati secara illegal sebab tidak ada bukti kepemilikan.

Dalam proses implementasi kebijakan pembangunan infrastruktur jalan kawasan ekonomi khusus kota bitung tentunya dalam proses prumusan kebijakannya sudah ada pembiayaan untuk semua program-programnya. Yang dibiayai dalam programnya. Pendapat dari Marillee S. Grindle sejalan dengan Undang- undang Nomor 39 tahun 2009 tentang Kawasan Ekonomi Khusus pasal 13 yang menyebutkan bahwa Pembiayaan untuk pembangunan dan pemeliharaan infrastruktur di dalam kawasan ekonomi khusus berasal dari Pemerintah pusat dan/atau pemerintah daerah, swasta, kerja sama antar pemerintah pusat, yang bertanggung jawab dalam pembangunan ini, masyarakat mengetahui pembangunan ini lewat isuisu yang berkembang di masyarakat sedangkan masyarakat tidak tau apa yang menjadi acuan pembangunan ini terutama masalah maksud dan tujuan pembangunan tersebut. Hal ini didukung juga oleh [3], bahwa agar program-progran terpat sasaran maka perlu adanya dukungan komun

pemerintah daerah dan swasta, atau sumber lain yang sah sesuai dengan ketentuan peraturan perundangundangan. Berdasarkan pendapat ahli dan berdasarkan Undang-undnag diatas dapat di simpulkan bahwa dalam setiap kebijakan sudah ada dan jelas pembiayaan program dan kegiatannya, selain itu juga dalam pembangunan infrastruktur jalan Kawasan Ekonomi khusus juga sudah jelas

sumber pembiayaanya dari pemerintah pusat, pemerintah daerah, swasta dan sumber lain yang sah sesuai dengan perundang-undangan.

\section{Partisipasi Masyarakat}

Partisipasi adalah suatu wujud dari peran serta seseorang dalam aktifitas berupa perencanaan dan pelaksanaan untuk mencapai tujuan pembangunan, dengan kata lain partisiasi berarti kesediaan untuk membantu berhasilnya setiap program sesuai dengan kemampuan setiap orang tanpa mengorbankan kepentingan diri sendiri, partisipasi berfungsi sebagai suatu kemitraan dengan pembangunan. Peneliti menemukan bahwa secara jelas masyarakat tidak berpartisipasi dalam proses pembangunan infrastruktur jalan kawasan ekonomi khusus sebab masyarakat terus meminta adanya ganti rugi sedangkan masyarakat tidak ada bukti kepemilikan, disini masyarakat tersebut bisa dianggap sebagai penghalang pembangunan. dalam proses pembangunan kawasan ekonomi khusus kota bitung disini diatur dalam peraturan pemerintah nomor 32 tahun 2014 tentang kawasan ekonomi khusus kota bitung yang termasuk dalam pasal 6 dijelaskan bahwa agar setiap mengetahui pembangunan kawasan ekonomi khusus maka memerintahkan perundangan Peraturan Pemerintah ini dengan penempatannya dalam Lembaran Negara Republik Indonesia. Dari penelitian ini ditemukan masalah bahwa masyarakat belum mengerti betul tentang tujuan pembangunan kawasan ekonomi tersebut sehingga masyarakat tidak mau berpartisipasi terutama dalam proses pembangunan infrastruktur jalan kawasan ekonomi khusus kota bitung, dan juga masyarakat yang meminta ganti rugi untuk lahan pembangunan infrastruktur jalan kawasan ekonomi khusus sedangkan lahan tersebut adalah lahan milik negara.

\section{Ucapan Terimakasih}

Terimakasih disampaikan kepada semua pihak yang boleh membanti dalam pelaksaan penelitian sehingga artikel ini dapat diselesaikan. 


\section{Kesimpulan}

Hasil penelitian menunjukkan bahwa 1) Pemerintah tidak mensosialisasikan secara langsung kepada masyarakat mengenai perencanaan dan perumusan kebijakan untuk pembangunan infrastruktur jalan kawasan ekonomi khusus, masyarakat juga tidak terlibat dalam proses perumusan dan perencanaan, dan dalam proses perencanaan dan perumusan kebijakan tersebut masyarakat hanya diwakili oleh pemerintah. 2) Proses pengawasannya tidka berjalan sesuai yang diharapkan, 3). Pemerintah sudah mengetahui dengan jelas mengenai aturan yang menjadi acuan dalam pembangunan infrastruktur jalan kawasan ekonomi khusus, 4) Masyarakat sebenarnya mengetahui konsekuensi yang akan diterima jika masyarakat tetap akan tinggal di lahan tersebut berdasarkan pengalaman- pengalaman yang terjadi yaitu penggusuran yang pernah dilakukan pemerintah tanggal 5 februari 2016 karena masyarakat ttidak memiliki bukti kepemilikan yang sah. Pemerintah sudah bernegosiasi untuk pemberian pemukiman baru yaitu rumah susun tetapi masyarakat tetap tidak setuju. 5) Pemerintah tidak konsisten dengan upaya yang dilakukan yaitu pembangunan infrastruktur jalan kawasan ekonomi khusus lahan pembangunan yanag sudah jelas milik negara seharusnya tidak ada penghuni sebelum dilakukan pembangunan. seharusnya pemerintah sudah mengetahui terlelih dahulu keadaan lingkungan sekitar, selanjutnya pembangunan untuk kepentingan umum tidak seharusnya diberhentikan. 6) Masyarakat terus bersih keras bahwa lahan pembangunan infrastruktur jalan kawasan ekonomi khusus kota bitung adalah lahan mereka sedangkan sudah jelas diatur dalam sertifikat HPL nomor 2 tahun 2018 bahwa lahan tersebut merupakan lahan milik pemerintah provinsi sulawesi utara. Dalam masalah ini pemerintah berusaha mengambil jalan tengah yaitu pemindahan masyarakat dirumah susun tetapi masyarakat yang tetap tidak setuju dengan jelas membuat pembangunan infrastruktur jalan kawasan ekonomi khusus terhenti sementara. 7) Dari penjelasan sebelumnya bahwa masyarakat tidak berpartisipasi dalam proses pembangunan infrastruktur jalan kawasan ekonomi khusus sebab masyarakat terus menuntut yang bukan hal mereka. Dengan tidak adanya partisipasi masyarakat setempat seperti ini maka pemerintah menganggap bahwa mereka adalah masyarakat illegal, tanpa bukti kepemilikan dan untuk tahap selanjutnya pemerintah akan tetap melanjutkan pembangunan infrastruktur jalan kawasan tersebut secepatnya. Untuk itu disarankan bahwa, 1) yaitu rumah susun tetapi

[3] D. S. Van Meter and C. E. Van Horn, "The Policy Implementation Process: A Conceptual Framework," Adm. Soc., 1975. masyarakat tetap tidak setuju. 5) Pemerintah tidak konsisten dengan upaya yang dilakukan yaitu pembangunan infrastruktur jalan kawasan ekonomi khusus lahan pembangunan yanag sudah jelas milik negara seharusnya tidak ada penghuni sebelum dilakukan pembangunan. seharusnya pemerintah sudah mengetahui terlelih dahulu keadaan lingkungan sekitar, selanjutnya pembangunan untuk kepentingan umum tidak seharusnya diberhentikan. 6) Masyarakat terus bersih keras bahwa lahan pembangunan infrastruktur jalan kawasan ekonomi khusus kota bitung adalah lahan mereka sedangkan sudah jelas diatur dalam sertifikat HPL nomor 2 tahun 2018 bahwa lahan tersebut merupakan lahan milik pemerintah provinsi sulawesi utara. Dalam masalah ini pemerintah berusaha mengambil jalan tengah yaitu pemindahan masyarakat dirumah susun tetapi masyarakat yang tetap tidak setuju dengan jelas membuat pembangunan infrastruktur jalan kawasan ekonomi khusus terhenti sementara. 7) Dari penjelasan sebelumnya bahwa masyarakat tidak berpartisipasi dalam proses pembangunan infrastruktur jalan kawasan ekonomi khusus sebab masyarakat terus menuntut yang bukan hal mereka. Dengan tidak adanya partisipasi masyarakat setempat seperti ini maka pemerintah menganggap bahwa mereka adalah masyarakat illegal, tanpa bukti kepemilikan dan untuk tahap selanjutnya pemerintah akan tetap melanjutkan pembangunan infrastruktur jalan kawasan tersebut secepatnya. Untuk itu disarankan bahwa,1)Pemerintah perlu mengkomunikasikan terlebih dahulu kepada masyarakat lewat sosialisasi- sosialisasi secara langsung.2) Perlu dilakukan survei terlebih dahulu mengenai Kondisi Lingkungan Sosial Ekonomi dan Politik di daerah Pembangunan infrastruktur jalan Kawasan Ekonomi Khusus,. 3) Pemerintah selaku Dewan Nasional Kawasan Ekonomi Khusus

Perlu melakukan koordinasi dengan Pemerintah Kota Bitung mengenai pembiayaan perolehan lahan. 4) Dalam proses pengawasan pihak Dewan Kawasan Ekonomi Khusus perlu bekerja sama dengan baik dengan Kantor Administrator Kawasan Ekonomi Khusus Kota Bitung, agar tercpainya tujuan yang diharapkan. 5) Kemudian juga perlu adanya kepastian kepemilikan lahan pembangunan infrastruktur jalan kawasan ekonomi khusus kota bitung, 6) perlu dilakukan penjelasan secara mendalam tentang maksud dan tujuan pembangunan infrastruktur jalan kawasan ekonomi khusus ini kepada masyarkat.

\section{Referensi}

[1] Sugiyono, Metode Penelitian Kuatintatif, Kualitatif dan $R \& D .2008$.

[2] G. C. Edward III, "Public Policy Implementing," Literary and Linguistic Computing. 1984

[4] A. Gilbert, "Merilee S. Grindle (ed.): Politics 
and Policy Implementation in the Third World (Princeton: Princeton University Press, 1980, $£ 11.00$ cloth, $£ 4.45$ paper). Pp. xv +310 .," J. Lat. Am. Stud., 1983.

[5] Undang Nomor 39 Tahun 2009 tentang Kawasan Ekonomi Khusus.

[6] Peraturan Pemerintah Nomor 32 Tahun 2014 tentang Kawasan Ekonomi Khusus Kota Bitung.

[7] Sekretariat Dewan Nasional KEK. "Dewan Nasional Kawasan Ekonomi Khusus" KEK. 2018

[8] AABot. "Kawasan Ekonomi Khusus" Wikipedia. 2019 